\title{
Factors Influencing the Uptake of Short Term Contraceptives Among Women in Afghanistan: Further Analysis of Afghanistan Demographic and Health Survey 2015 (A Cross Sectional Study)
}

Ahmad Siyar Noormal ( $\nabla$ siyarnoormal@gmail.com )

Heidelberg Institute of Global Health

Volker Winkler

Heidelberg Institute of Global Health

Ali Maisam Eshraqi

Kabul Medical University

Andreas Deckert

Heidelberg Institute of Global Health

Iftekhar Sadaat

Ministry of Public Health

Peter Dambach

Heidelberg Institute of Global Health

\section{Research Article}

Keywords: Short term contraceptives, FP, Sociodemographic, Women empowerment, Fertility, Birth spacing

Posted Date: August 17th, 2021

DOI: https://doi.org/10.21203/rs.3.rs-778603/v1

License: (c) (1) This work is licensed under a Creative Commons Attribution 4.0 International License. Read Full License 


\section{Abstract}

Objective: The aim of this study is to assess factors that influence the uptake of short term contraceptives among married women aged between 15-49 years in Afghanistan.

Method: The cross sectional Afghanistan 2015 Demographic and Health Survey provided the dataset for this analysis. We included 22,974 women and applied multivariable logistic regression to investigate the influencing factors for the uptake of short term contraceptives.

Results: $95 \%$ of Afghan women knew at least one type of contraception but only $16 \%$ were using short term contraceptives. Short term contraceptive use was most prevalent among women in the age group between 30 and 40 who were educated, employed, and rich. Most of users were living in the western parts of Afghanistan and belong to Balooch and Pashtun ethnic groups. Media exposure and women empowerment were also positively associated with the use of short term contraceptives. However, we did not find an association with living in urban or rural settings.

Conclusion: FP in Afghanistan requires multisectorial efforts, tailored to the needs of women stemming from low and middle socioeconomic status. Health promotion 5 activities, empowering women, strengthening education, and training of FP service providers on effective counseling are good options to address the issue.

\section{Background}

According to the World Health Organization, 'Family Planning (FP) allows people to attain their desired number of children and determine the spacing of pregnancies. It is achieved through use of contraceptive methods and the treatment of infertility'. FP is an effective approach to reduce maternal and child mortality $(1,2)$ and studies have shown, that contraceptives prevent about one third of pregnancy related deaths, and $44 \%$ of neonatal deaths(3).

Globally, about $12 \%$ of married women have an unmet need for contraception and most of them are living in low and middle income countries (4). Recent data showed that in 2017 out of 206 million pregnancies in developing countries, around $43 \%$ of them were unintended. According to WHO, around 214 million women of reproductive age, who want to avoid pregnancy are not using any method of contraception(5). This unmet need for contraception results in millions of unwanted pregnancies(5). Studies showed that promotion of contraceptives in developing countries over the past 2 decades has avoided up to $40 \%$ of maternal deaths simply by reducing the number of unwanted pregnancies(6).

According to recent data(7), the pregnancy related mortality ratio in Afghanistan was 1,291 per 100,000 live births in 2017, however some contradicting figures show lower numbers 638 (8), which still stands among the highest in the world(7). Traditionally, Afghans prefer large families, and even though the fertility rate has been declining during the last years from 7.4 in 2000, to 4.5 in 2017, the total fertility rate is still considered high compared to its South Asian neighbors.(9) Afghan stakeholders and policymakers 
consider FP as an effective approach to tackle maternal and child mortality, and therefore initiated several programs to promote FP in Afghanistan.

Over the past decade, there was an increase in the prevalence of contraceptive use from $7 \%$ in 2003 over $11 \%$ in 2012 to a still low $23 \%$ in 2015.(10) Bearing the high fertility rate in Afghanistan in mind, this rate is considered low compared to other countries all over the world.(11) The report of AfDHS in 2015 showed that $95 \%$ of married women and $92 \%$ of married men know at least one method of FP.(7) Despite this high level of awareness, the prevalence of contraception utilization was $23 \%$, which were composed of more than $15 \%$ short term contraceptives, $3 \%$ traditional methods, and less than $4 \%$ intrauterine devices, fertilization and implants.(7)

Contraceptives may either be classified as modern and traditional methods, or according to the duration of their effectiveness as long term, short term, and permanent contraceptives. Recently, another study analyzed the factors which influence the uptake and unmet need of modern contraceptives in Afghanistan, and found parity, education, ethnicity, media exposure, and wealth index to be determinants of modern contraceptive uptake.(12) Since oral contraceptives, injectables, and male condoms, which are classified as short term methods,(13) were the most widely known and practiced methods among both women and men, our analysis explicitly focuses on barriers to short term contraceptives and investigates if it differs from what it is already known about modern and other types of contraception.

\section{Hypothesis}

Use of short term contraceptive methods in Afghanistan is influenced by women's sociodemographic characteristics, exposure to FP Information, and women's empowerment.

\section{Methodology}

We used the nationally representative Afghanistan Demographic and Health Survey 2015 (AfDHS) dataset. Data collection was carried out between July 15, 2015 and February 23, 2016. The AfDHS 2015 used an updated version of the Household Listing Frame as sampling frame(14), which included information of 25,974 enumeration areas (EAs). The required number of households was estimated for each EA using location (province, and district) and type of residence (urban or rural).(7)

The stratified two stage random sample design resulted in representative estimates of demographic and health indicators. Details on the data collection process can be found elsewhere.(7) All ever married women between the age of 15-49 years who were permanent residents of the selected households or visitors who stayed in the households the night before the survey were eligible for the survey. Participant have agreed to take part in the survey and signed the consent form. Since pregnant women will definitely 
not utilize contraception and including them in the analysis could increase the discriminatory power of the analysis, women who were pregnant at the time of survey were excluded for this analysis.

A total of 29,461 women out of 30,434 eligible women (response rate $96.8 \%$ ) were interviewed in the survey. Out of these, we excluded 6,514 women (22.1\%) who were pregnant at the time of data collection, hence, remained with a total of 22,947 women (Fig. 1).

The survey protocol was approved by the Inner City Fund (ICF) Institutional Review Board and the Ministry of Public Health of Afghanistan. The data from this survey are openly available under https://dhsprogram.com/data/available datasets.cfm.

The outcome for this analysis was the current use of short term contraceptives as binary indicator. As potential explanatory variables we considered: age, education, wealth index, occupation, place of residence, ethnicity, region, media exposure, and women empowerment. Media exposure was created from the questions that asked the women if they had heard of FP messages from TV, radio, or magazines. Based on this the participants were categorized as 'exposed to FP information' if they affirmed to at least one of these questions. The binary variable women empowerment was created based on questions on the woman's involvement in household decisions on income, purchases, family visits, and their health. Women were categorized 'empowered' if they were involved in at least in one of these decisions.

For the descriptive analysis we used Pearson's Chi square tests to assess the existence of an association between the use of short term contraceptives and the explanatory variables. Then we used logistic regression to estimate odds ratios for the independent variables.

Since the dataset was huge, and all the variables were found to be significant at level of $95 \%$ confidence interval, we decided for more strict criteria to minimize the risk of chance and set the statistical significance to $a=0.01$ and calculated $99 \%$ of confidence intervals with robust standard errors. Stata version $12 \mathrm{IC}$ was used for analyses.

\section{Results}

Overall use of short term contraceptives was quite low: Among the total of 22,947 participants, only $17 \%$ used short term contraceptives; however, almost $92 \%$ had knowledge of at least one short term method of contraception.

\section{Sociodemographic distribution and use of short term contraceptives}

Table 1 shows that the majority (20.3\%) of the participants (non pregnant women) in this survey were between $25-29$ years old, followed by the age group of $20-24$ (18\%). Over $85 \%$ of women were illiterate, 
and around $87 \%$ of the participants were unemployed. Almost three quarters of the participants belonged to Pashtun and Tajik ethnic groups. Three quarter $(74.4 \%)$ of the women were living in rural areas. The number of women who did not have access to FP information was almost twice as high as of those who had access. Moreover, more than $63 \%$ of women were involved in at least one of the household decisions, thus, were considered to be empowered. 
Table 1

Socio-Demographic characteristics of women tested against the outcome short-term contraceptive Use.

\begin{tabular}{|c|c|c|c|c|}
\hline \multirow[t]{2}{*}{ Variables } & \multirow[t]{2}{*}{ Total Number of women } & \multicolumn{2}{|c|}{ Use of short-term contraceptives } & \multirow[t]{2}{*}{$\mathrm{p}$-value } \\
\hline & & Number & Percentage & \\
\hline Age of mother & & & & $<0.0001$ \\
\hline $15-19$ & $1,189(5.18 \%)$ & 84 & $7.1 \%$ & \\
\hline $20-24$ & $4,270(18.6 \%)$ & 584 & $13.7 \%$ & \\
\hline $25-29$ & $4,656(20.3 \%)$ & 881 & $18.9 \%$ & \\
\hline $30-34$ & $3,414(14.9 \%)$ & 712 & $20.9 \%$ & \\
\hline $35-39$ & $3,495(15.2 \%)$ & 739 & $21.1 \%$ & \\
\hline $40-44$ & $2,903(12.7 \%)$ & 562 & $19.4 \%$ & \\
\hline $45-49$ & $3,020(13.2 \%)$ & 332 & $11.0 \%$ & \\
\hline Education level & & & & $<0.0001$ \\
\hline No Education & $19,690(85.8 \%)$ & 3,200 & $16.3 \%$ & \\
\hline Primary & $1,519(6.6 \%)$ & 322 & $21.2 \%$ & \\
\hline Secondary & $1,345(5.9 \%)$ & 280 & $20.8 \%$ & \\
\hline Higher Education & $393(1.7 \%)$ & 92 & $23.4 \%$ & \\
\hline Wealth Index & & & & $<0.0001$ \\
\hline Poorest & $4,342(18.9 \%)$ & 646 & $14.9 \%$ & \\
\hline Poorer & $5,041(22.0 \%)$ & 673 & $13.4 \%$ & \\
\hline Middle & $4,917(21.4 \%)$ & 716 & $14.6 \%$ & \\
\hline Richer & $4,974(21.7 \%)$ & 912 & $18.3 \%$ & \\
\hline Richest & $3,673(16.0 \%)$ & 947 & $25.8 \%$ & \\
\hline Women Occupation & & & & $<0.0001$ \\
\hline Employed & $2,858(12.4 \%)$ & 400 & $14.0 \%$ & \\
\hline Unemployed & $20,070(87.5 \%)$ & 3,492 & $17.4 \%$ & \\
\hline Missing & $19(0.1 \%)$ & & & \\
\hline Place of Residence & & & & $<0.0001$ \\
\hline Rural & $17,073(74.4 \%)$ & 2,582 & $15.1 \%$ & \\
\hline
\end{tabular}




\begin{tabular}{|c|c|c|c|c|}
\hline \multirow[t]{2}{*}{ Variables } & \multirow[t]{2}{*}{ Total Number of women } & \multicolumn{2}{|c|}{ Use of short-term contraceptives } & \multirow[t]{2}{*}{$\mathrm{p}$-value } \\
\hline & & Number & Percentage & \\
\hline Urban & $5,874(25.6 \%)$ & 1,312 & $22.3 \%$ & \\
\hline Ethnicity & & & & $<0.0001$ \\
\hline Pashtun & $9,531(41.5 \%)$ & 1,656 & $17.4 \%$ & \\
\hline Tajik & $7,141(31.1 \%)$ & 1,432 & $20.1 \%$ & \\
\hline Hazara & $2,258(9.8 \%)$ & 428 & $19.0 \%$ & \\
\hline Uzbek & $1,604(7.0 \%)$ & 175 & $10.9 \%$ & \\
\hline Turkmen & $474(2.1 \%)$ & 33 & $7.0 \%$ & \\
\hline Nooristani & $877(3.8 \%)$ & 9 & $1.0 \%$ & \\
\hline Baloch & $291(1.3 \%)$ & 74 & $25.4 \%$ & \\
\hline Pashai & $405(1.8 \%)$ & 28 & $6.9 \%$ & \\
\hline Other & $325(1.4 \%)$ & 56 & $17.2 \%$ & \\
\hline Missing & $41(0.2 \%)$ & 1,656 & & \\
\hline Region & & & & $<0.0001$ \\
\hline Central & $3,991(17.4 \%)$ & 806 & $20.2 \%$ & \\
\hline North Eastern & $2,562(11.2 \%)$ & 296 & $11.6 \%$ & \\
\hline North Western & $3,157(13.8 \%)$ & 330 & $10.5 \%$ & \\
\hline Eastern & $2,980(13.0 \%)$ & 239 & $8.0 \%$ & \\
\hline Western & $3,439(15.0 \%)$ & 1,040 & $30.2 \%$ & \\
\hline South Eastern & $3,531(15.4 \%)$ & 424 & $12.0 \%$ & \\
\hline South Western & $3,287(14.3 \%)$ & 759 & $23.1 \%$ & \\
\hline Access to Family Pla & ing Information & & & $<0.0001$ \\
\hline Yes & $8,451(36.8 \%)$ & 1,895 & $22.4 \%$ & \\
\hline No & $14,411(62.8 \%)$ & 1,989 & $13.8 \%$ & \\
\hline Missing & $85(0.4 \%)$ & & & \\
\hline Women Empowerme & & & & $<0.0001$ \\
\hline Empowered & $14,058(61.3 \%)$ & 2,596 & $18.5 \%$ & \\
\hline Not Empowered & $8,023(35.0 \%)$ & 1,292 & $16.0 \%$ & \\
\hline
\end{tabular}




\begin{tabular}{|c|c|c|c|c|}
\hline \multirow[t]{2}{*}{ Variables } & \multirow[t]{2}{*}{ Total Number of women } & \multicolumn{2}{|c|}{ Use of short-term contraceptives } & \multirow[t]{2}{*}{ p-value } \\
\hline & & Number & Percentage & \\
\hline Missing & $866(3.8 \%)$ & & & \\
\hline Total & $22,947(100 \%)$ & 3,894 & & \\
\hline
\end{tabular}

\section{Multivariable logistic regression analysis}

The result from multiple logistic regression revealed an association between all the predicting factors and use of short term contraception. The only factors which was not significantly ( $p$ value $=0.58$ ) associated was the place of residence and we did not find any significant difference in the use of short term contraception among women living in urban and rural settings (Table 2). 
Table 2

Crude and adjusted odds ratios and the corresponding confidence intervals of contraceptive use regressed on the predictor variables (link function: logit)

\section{Bivariate Model Full Model}

\begin{tabular}{|lllll} 
Variables & $\begin{array}{l}\text { Crude } \\
\text { Odds } \\
\text { ratio }\end{array}$ & $\begin{array}{l}95 \% \text { Confidence } \\
\text { Interval (Cl) }\end{array}$ & $\begin{array}{l}\text { Adjusted } \\
\text { Odds ratio }\end{array}$ & $\begin{array}{l}95 \% \text { Confid } \\
\text { Interval (Cl) }\end{array}$ \\
Women age group & & & & \\
\hline $15-19$ & 0.62 & $0.48-0.79$ & 0.47 & $0.33-0.65$ \\
\hline $20-24$ & 1.28 & $1.11-1.48$ & 1.09 & $0.89-1.33$ \\
\hline $25-29$ & 1.89 & $1.65-2.16$ & 1.76 & $1.46-2.12$ \\
\hline $30-34$ & 2.13 & $1.85-2.46$ & 2.00 & $1.64-2.42$ \\
\hline $35-39$ & 2.17 & $1.89-2.50$ & 1.98 & $1.63-2.40$ \\
\hline $40-44$ & 1.94 & $1.68-2.25$ & 1.86 & $1.52-2.27$ \\
$45-49$ & $\begin{array}{l}(1) \\
\text { Reference }\end{array}$ & & $\begin{array}{l}(1) \\
\text { Reference }\end{array}$ & $0.33-0.65$ \\
\hline
\end{tabular}

Education level

0.002

No Education

(1)

Reference

(1)

Reference

Primary

1.39

$1.29-1.58$

1.28

1.06-1.55

Secondary

1.35

1.18-1.55

1.19

0.97-1.46

High School

1.58

1.24-1.99

1.01

$0.70-1.45$

Ethnicity

Pashtun

Tajik

Hazara

Uzbek

Turkmen

Nooristani

Balooch

Pashai
(1)

Reference

1.19

1.11

0.58

0.36

0.05

1.62

0.35
$1.10-1.29$

0.99-1.25

0.49-0.69

$0.25-0.51$

0.02-0.09

1.24-2.12

0.24-0.52

Page 9/18
(1)

Reference

0.95

0.83-1.08

0.93

0.78-1.12

0.90

0.68-1.18

0.55

$0.33-0.92$

$0.04-0.23$

0.10

0.88-1.92

1.30

$0.29-0.83$ 
Bivariate Model

Other

0.99

$0.74-1.33$

Wealth Index

Poorest

(1)

Reference

Poorer

Middle

Richer

Richest

Women Occupation

Unemployed

(1)

Reference

Employed

0.77

0.98

1.28

1.99

$0.69-0.86$

$0.78-0.99$

0.87-1.09

$1.15-1.43$

$1.78-2.22$

Full Model

1.00

$0.65-1.54$
(1)

Reference

1.14

0.97-1.35

1.32

$1.11-1.56$

1.59

$1.34-1.89$

$1.64-2.55$
$1.10-1.57$

Place of residence

Urban

(1)

Reference

(1)

Reference

Rural

0.62

$0.57-0.67$

1.03

$0.89-1.20$

Region

Central

(1)

Reference

(1)

Reference

North Eastern

0.52

0.46

0.34

1.71

0.54

1.19

South Western

Media Exposure

Do not have access

to FP information
(1)

Reference
$0.45-0.59$

$0.40-0.53$

$0.29-0.40$

$1.54-1.90$

$0.47-0.61$

$1.06-1.33$
0.55

0.50

0.49

2.17

0.53

1.23 
Bivariate Model

Have access to FP information

1.81
$1.81 \quad 1.68-1.94$

Women Empowerment

Not Empowered

(1)

Reference

1.18

Empowered

As shown in Table 2, the chance of using contraceptives was lowest in the youngest age group, compared to the oldest, and increased with age up to 30-39 years, while it decreased again afterwards. Women in the age group of $\{30-40\}$ were nearly 4 times more likely to use short term contraceptives compared to young women and 2 times more than those at older ages. Education level was also significantly associated with the use of short term contraceptives. Women who had primary education were more likely to adhere to the use of contraceptives compared to illiterate women however the association with secondary and higher education is not significant. An increase in the wealth index was also significantly associated with the uptake of short term contraceptive use. Employed women were more likely to use short term contraceptives compared to unemployed women. Region of residence equally played an important role in the uptake of contraceptives in Afghanistan (Table 2). Regarding ethnicity, only Balooch women did use short term contraceptives significantly more often compared to other ethnic groups, while Turkman and Pashai women had the lowest ratios. The usage of short term contraceptives was very high among women in the western region compared to the other 6 regions. Women living in the North Eastern, North Western, Eastern, and South Eastern regions were least likely to use short term contraceptives compared to those living in the central region. Access to FP information also showed a strong association with short term contraceptive uptake. Women who have had access to FP information were 1.4 times more likely to use short term contraceptives compared to those who did not have access. Empowered women were almost 1.2 times more likely to use short term contraceptives compared to those who were not empowered.

\section{Discussion}

The dataset was huge and all the predictors were significant in the univariate model except place of residence, therefore we performed the full model analysis. However we first decided to make the final model through the backward elimination method, but since the data was hardly changing with that, we included all the variables in the final model.

Our results highlight that most of the sociodemographic characteristics of a woman (age, literacy, marital status, wealth, ethnicity, region, access to FP information and women empowerment) were significantly associated with the uptake of short term contraceptive which is in line with our hypothesis. These results mostly follow the findings of several studies in the region and all over the world (16-20), however the 
place of residence did not make a significant difference which was not similar to what was already known in the region (15).

Similar to several studies in the region and other developing countries, $(17,18,21)$ our study revealed that age of women was associated with the uptake of contraceptives. In our study, the prevalence of short term contraceptive uptake was higher among women aged between 30-40 years old while women younger than 20 years had the lowest rate. This could be due to several reasons: they are newly married and do not want to avoid pregnancy; these women are less aware of the methods; reproductive health is still a taboo and thus, young women feel ashamed to talk about such issues and to seek FP services.

Similar to other studies conducted in the region $(22,23)$ our study found a strong association between employment and use of short term contraception. We found that women who were working outside the home, regardless of the type of occupation, were more likely to use contraceptives.

Ethnicity and region also play a role in the usage of contraception. Women living in the western parts of country were more likely to use contraceptives compared to those who are living in the eastern and central parts. Similarly, the prevalence of short term contraceptives is very low among Nooristani women who are living in the eastern parts of the country. The basic conception for this variation could be the geography and security issues which could restricts the provision of health service in these regions.

Access to FP information is an important factor for contraceptive uptake. In the DHS survey women were already considered as knowledgeable only if they were able to name at least one method of FP. Having stated in the DHS survey to know about contraceptives does not necessarily mean that knowledge about its correct application is prevalent nor does it determine actual use. What we looked at in our study was their exposure to FP information which we assumed, increased their knowledge about the methods, the benefits, side effects and further aspects of FP. This finding is similar to other studies which have been conducted in the region and in other developing countries.(24-26) Moreover if we look towards other aspects there could be discrepancies between knowledge and empowerment. The strong cultural anchor of having big families plays an important role which puts women under the pressure to bear as many children as possible and not use contraceptives, even they have the knowledge.

In our study we only looked at media exposure, and due to a huge amount of missing values in the dataset, we did not include other channels (exposure at the health facility and information through community health workers). We found a significant association between media exposure and short term contraceptive uptake and we think that if we would have been able to include other channels into our analysis, the association might have become stronger. In the women empowerment category, we categorized women as empowered if they had answered positive to at least one of those four questions. This was a conservative approach and if we had used stricter criteria, then the effect would have been much stronger and the influence of real empowerment most probably much higher.

\section{Barriers of contraception uptake:}

Page $12 / 18$ 
Poor access to contraception, insufficient information about free provision of FP services, fear of side effects, insecurity, cultural and religious disagreements, and gender issues are considered potential barriers for contraception uptake in Afghanistan.

Since we only conducted a quantitative analysis, we identified some of the potential barriers, but there might be some underpinning factors and barriers which need investigation using qualitative research methods with women of reproductive age.

\section{Recommendations}

FP is a wide area which requires a multisectoral collaboration and approach to promote in the society. Community based provisions and the use of community health workers (CHWs) to educate both men and women and provide FP services is recommended. Mass media should be used to promote and advocate for FP. Since Afghanistan is a religious country, one of the effective approaches to advocate for the promotion of FP would be to use religious leaders in the society. Inclusion of FP methods as clinical attachments or part of the medical and nursing curriculum, and conducting regular trainings for service providers on proper counseling are also known to be effective approaches for contraceptive promotion. Improving logistics and supply chain management specifically in the eastern parts of the country would be an important action.

We also suggest to conduct qualitative research on non use and discontinuation of methods to find out why women do not use or stop using contraceptives. Conducting FGDs and In-depth interviews not only with women but also with husbands and in laws about different aspects of FP such as expectations of the society, decision making regarding FP, and level of knowledge on contraception, is highly recommended.

The above mentioned recommendations could serve the Afghan policymakers to develop and implement interventions based on empirical evidence which may contribute to the improvement of the health sector, especially the field of mother and child health.

\section{Strengths and limitations}

Using DHS data provides us with a trustworthy source and good data quality compared to many single studies. However, in the original study it was assumed that security issues might not have allowed to cover all the selected areas, therefore 101 reserve clusters were selected for replacement and later on 70 clusters, replaced the areas which were identified insecure. At the end the AfDHS was unable to collect data from Zabul province in the south eastern region because it was inaccessible for security reasons. Taking this into account, our results could have looked differently if the initially selected cluster had been used.

The large sample size of 22,974 participants provides a solid basis for statistically robust uni and multivariable analyses. Since the dataset was huge and all the variables were significant, conservatively we used a very strict confidence interval of $99 \%$, which is considered a strength of the study. On the other 
hand, the cross sectional design of the study restricts the establishment of causal relationships between outcome and exposure. Moreover, some of the potential influencing factors such as number of children, distance from the health facility, number of ANC visits were not included in this study which might have introduced some residual confounding to this analysis. Also, men were not included in this analysis.

Additionally, the dataset had $44(0.2 \%)$ missing values for ethnicity, $19(0.1 \%)$ missing values for occupation, access to FP information had $85(0,4 \%)$ missing values and the women empowerment variable had 866 (3.8\%) missing values. Regarding the women empowerment variable, most probably the questions were too sensitive to be answered by all which resulted in information bias. Since these missing values were counting less than $5 \%$ of our sample size, we did the complete case analysis.

\section{Conclusion}

Our findings reveal that knowledge of short term contraceptives was $92 \%$ among all ever married women, while only $16 \%$ of women were using these methods. Lack in access to FP services is a potential barrier for the use of short term contraceptives, which itself is driven by security, geography, wealth, awareness and even women's age. From the findings of our study we can extract the following implications which might be helpful for the government if considered during their interventions in the area of maternal and child health: 1) more efforts are needed to increase the FP awareness and knowledge among men and women; 2) intersectoral collaboration (between health, education, women affairs, religious affair etc.) should be increased to provide opportunities for the women to improve their education level; 3) work with other agencies to improve the employment opportunities for women; 4) and implement interventions such as campaigns at the community level to empower women.

\section{Abbreviations}

FP Family Planning

DHS Demographic and Health Survey

FGD Focus Group Discussion

WHO World Health Organization

ICF Inner City Fund

CHW Community Health Workers

\section{Declarations}

\section{Acknowledgements}


We greatly acknowledge the DHS program granting access to the 2015 Afghanistan Demographic and Health Survey data. The tireless support and cooperation given by the entire team of the Heidelberg Institute of Global Health as well as DAAD scholarship is highly acknowledged.

\section{Declaration of interest}

The authors report no conflicts of interest.

\section{Details of ethical approval}

Since we used the secondary data from DHS, we did not need ethical clearance for this analysis as this survey was already approved by the IRB of Afghan Ministry of Public Health. Participant have agreed to take part in the survey and signed the consent form.

\section{Data Sharing}

We used the Afghanistan DHS 2015 dataset which is openly available under https://dhsprogram.com/data/available-datasets.cfm.

\section{Consent for publication}

Not applicable

\section{Details of funding.}

No funding was received for carrying out this research.

\section{Author Contributions}

SN and PD, conceived and planned the research. SN developed the theory, designed the model and the computational framework, analyzed the data, and wrote the manuscript with close coordination of PD and VW. VW contributed to the analysis of the data and advised and supervised the whole process of data analysis. IS contributed in developing the idea of research, data cleaning process, and data analysis. $A D$ contributed to data analysis and critically provided feedback on the revision of the manuscript. AME provided critical feedback and helped shape the research, analysis and data interpretation. All authors approved the version to be published.

\section{References}


1. Bongaarts, J. Does Family Planning Reduce Infant Mortality Rates? Population and Development Review, 13 (2), 323-334 (1987).

2. Ahmed, S., Li, Q., Liu, L. \& Tsui, A. O. Maternal deaths averted by contraceptive use: an analysis of 172 countries. The Lancet, 380 (9837), 111-125 (2012).

3. Shaw, D. The ABC's of Family Planning University of British Columbia Vancouver; 2010.

4. United Nations. Trends in Contraceptive Use Worldwide (Department of Economic and Social Affairs Population Division, New York, 2015).

5. World Health Organization. Family planning/Contraception.: World Health Organization; 2018 [Available from: https://www.who.int/news-room/fact-sheets/detail/family-planning-contraception.

6. Cleland, J. et al. Contraception and health. The Lancet, 380 (9837), 149-156 (2012).

7. Central Statistics Organization Afghanistan. Ministry of Public Health, ICF a. Afghanistan Demographic and Health Survey (ADHS) 2015 (Central Statistics Organization, Kabul Afghanistan, 2017).

8. World Health Organization. Maternal mortality in 2000-2017 2019 [cited 2020 02. April]. Available from: https://www.who.int/gho/maternal_health/countries/afg.pdf.

9. Un.org. World Population Prospects: The 2017 Revision | Multimedia Library - United Nations Department of Economic and Social Affairs. United Nations2019 [updated 21. june. 2017; cited 2019 04. May]. Available from: https://www.un.org/development/desa/publications/world-populationprospects-the-2017-revision.html.

10. Osmani, A. K. et al. Factors influencing contraceptive use among women in Afghanistan: secondary analysis of Afghanistan Health Survey 2012. Nagoya J Med Sci, 77 (4), 551-561 (2015).

11. WoldBank. Contraceptive prevalence, any methods (\% of women ages 15-49): The World Bank Data; 2019 [Available from: https://data.worldbank.org/indicator/SP.DYN.CONU.ZS.

12. Sabawoon, A., Anwar, A. \& Behzad, A. Factors affecting contraceptive use and unmet need among currently married women in Afghanistan: further analysis of the 2015 Afghanistan Demographic and Health Survey DHS working papers. 2018.

13. Tibaijuka, L. et al. Factors influencing use of long acting versus short acting contraceptive methods among reproductive age women in a resource limited setting. BMC Womens Health, 17 (1), 25 (2017).

14. ICF I. Demographic and Health Survey Sampling and Household Listing Manual (MEASURE DHS, Calverton, Maryland, U.S.A, 2012).

15. Rasooly, M. H. et al. Uptake and predictors of contraceptive use in Afghan women. BMC Womens Health, 15, 9 (2015).

16. Baksu, A. et al. Change in contraceptive choices and the effect of education on use of contraception at the family planning clinic of Sisli Etfal Training and Research Hospital, Istanbul, Turkey. Eur J Contracept Reprod Health Care, 10 (2), 98-104 (2005). 
17. Stephenson, R. et al. Contextual influences on modern contraceptive use in sub Saharan Africa. Am J Public Health, 97 (7), 1233-1240 (2007).

18. Okech, T. C., Wawire, D. N. W. \& Mburu, D. T. K. Contraceptive Use among Women of Reproductive Age in Kenya's City Slums. International Journal of Business and Social Science2011;2.

19. Novignon JNaJ. Trend and determinants of contraceptive use among women of reproductive age in Ghana.African Population Studies. 2014;28.

20. Adeyemi, A. S. et al. Contraceptive prevalence and determinants among women of reproductive age group in Ogbomoso, Oyo State, Nigeria. Open Access J Contracept, 7, 33-41 (2016).

21. Arbab, A. A., Bener, A. \& Abdulmalik, M. Prevalence, awareness and determinants of contraceptive use in Qatari women. East Mediterr Health J, 17 (1), 11-18 (2011).

22. Islam, A. Z. et al. Prevalence and Determinants of Contraceptive use among Employed and Unemployed Women in Bangladesh. Int J MCH AIDS, 5 (2), 92-102 (2016).

23. Hossain, M. B. et al. Identifying factors influencing contraceptive use in Bangladesh: evidence from BDHS 2014 data., 18 (1), 192 (2018).

24. Cohen, B. Family Planning Programs, Socioeconomic Characteristics, and Contraceptive Use in Malawi. World Dev, 28 (5), 843-860 (2000).

25. Okigbo, C. C. et al. Exposure to family planning messages and modern contraceptive use among men in urban Kenya, Nigeria, and Senegal: a cross sectional study. Reprod Health, 12, 63 (2015).

26. Zahra, F. \& Kahn, J. R. Does the Message Matter?: Family Planning Message Exposure and Women's Birth Spacing Intentions in Pakistan. 2017.

\section{Figures}




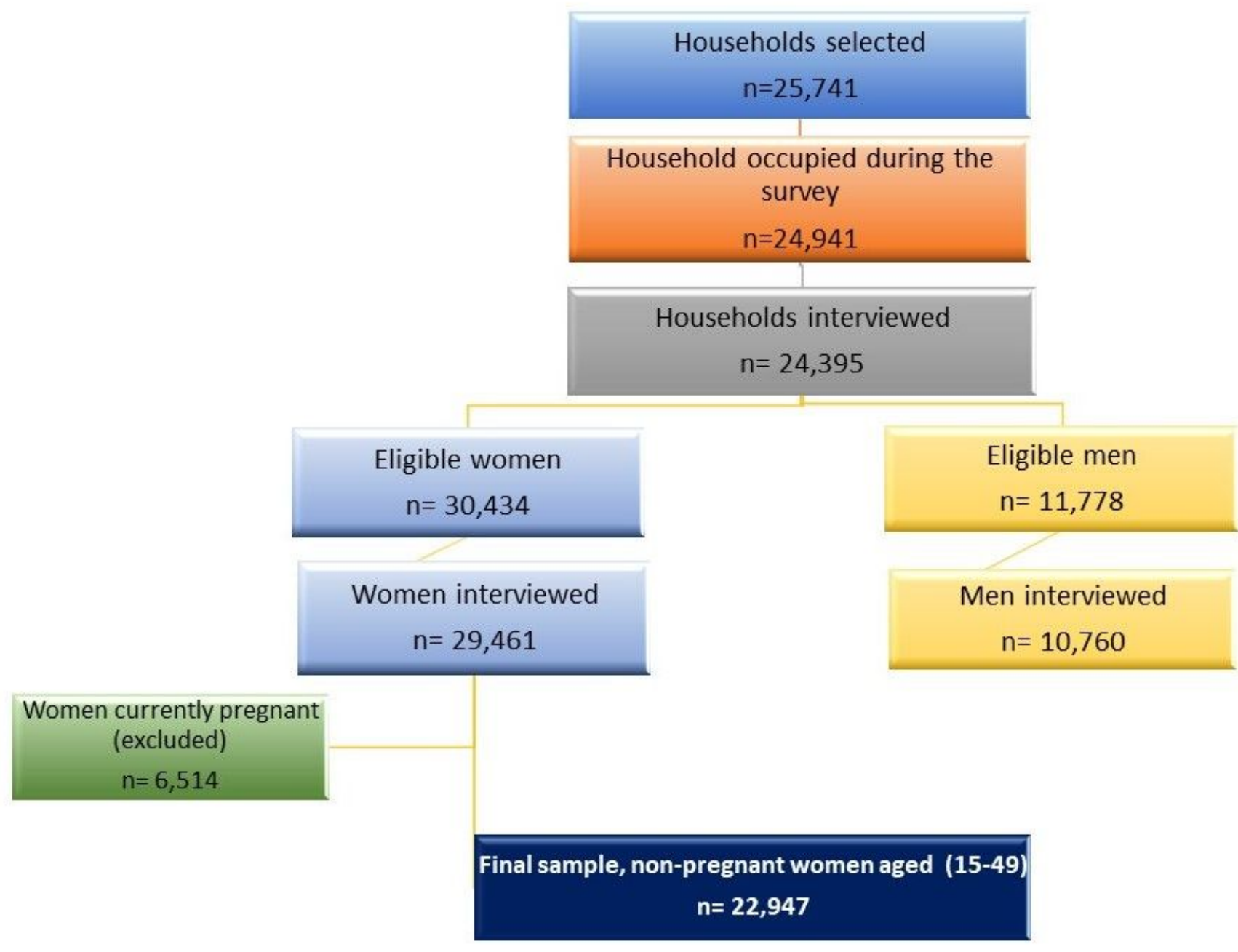

Figure 1

Flowchart of Participants 